\title{
Analysis of Work Posture and Work-Related Musculoskeletal Disorders with ROSA Method at Batam Environmental Service
}

\section{Analisis Postur Kerja dan Work-Related Musculoskeletal Disorders dengan Metode ROSA pada Dinas Lingkungan Hidup Kota Batam}

\author{
Arinda Soraya Putri, Dwinda Amalia \\ \{asp835@ums.ac.id,d600170045@student.ums.ac.id\}
}

Program Studi Teknik Industri, Fakultas Teknik, Universitas Muhammadiyah Surakarta

\begin{abstract}
Nowadays, computer is widely used in the work field. It is because computers can increase work efficiency and effectiveness. Dinas Lingkungan Hidup (DLH) Kota Batam facilitates its employees with computers to support their work activities in the office. The activity of using this computer is carried out in a sitting manner by office employees. Employees work posture such as sitting posture and duration of using computer which doesn't pay attention to the ergonomic side can causing muscle pain called Work-Related Musculoskeletal Disorders (WMSDs). The purpose of this study was to identify muscle complaints, analyze the risks of work posture and provide improvements to workers. The Rapid Office Strain Assessment (ROSA) method is used to determine the risk value of work activities using computers and sitting posture. In addition, the Nordic Body Map questionnaire is also used to determine the location of muscle complaints in workers. The results showed that 4 office employees have a risky work posture and there are 32 complaints of musculoskeletal pain felt by employees, where the most complaints were on the lower neck, waist and buttocks.

Based on these results, it is necessary to improve employees work posture and work facilities.
\end{abstract}

Keywords - ergonomic; musculoskeletal; Nordic Body Map; ROSA; work posture

Abstrak. Komputer pada masa kini merupakan alat yang banyak digunakan pada dunia kerja. Hal ini karena komputer dapat membantu pada efisiensi dan efektivitas kerja. Dinas Lingkungan Hidup (DLH) Kota Batam memfasilitasi pegawainya dengan komputer untuk menunjang aktivitas kerja di kantor. Aktivitas penggunaan komputer ini dilakukan dengan sikap duduk oleh pegawai kantor. Postur tubuh seperti sikap duduk dan durasi penggunaan komputer pada pekerja yang tidak memperhatikan sisi ergonomi dapat menimbulkan keluhan otot yang disebut dengan Work-Related Musculoskeletal Disorders (WMSDs). Tujuan dari penelitian ini adalah untuk mengidentifikasi keluhan otot, analisis resiko postur kerja dan memberikan usulan perbaikan pada pekerja. Metode Rapid Office Strain Assessment (ROSA) digunakan untuk mengetahui nilai resiko dari aktivitas kerja yang menggunakan komputer dan sikap duduk. Selain itu, kuesioner Nordic Body Map juga digunakan untuk mengetahui letak keluhan otot pada pekerja. Hasil penelitian yang diperoleh menunjukkan bahwa 4 pegawai kantor memiliki postur kerja yang beresiko dan keluhan otot yang dirasakan oleh pegawai sebanyak 32 keluhan dengan keluhan terbanyak adalah pada bagian leher bawah, pinggang dan bokong. Berdasarkan hasil tersebut maka diperlukan perbaikan pada postur kerja pegawai dan fasilitas kerja.

Kata kunci-ergonomi; muskuloskeletal; Nordic Body Map; ROSA; postur kerja;

\section{PENDAHULUAN}

Penggunaan komputer pada masa kini memiliki peran yang besar bagi pekerjaan. Penggunaan komputer dalam bekerja memiliki pengaruh pada efisiensi dan efektivitas kerja. Menurut Matos dan Pedro (2015) diketahui bahwa banyak pekerja kantor yang menghabiskan 75\% waktunya untuk duduk di depan komputer [1]. Penggunaan komputer yang tidak memperhatikan sisi ergonomi dapat mengalami berbagai macam keluhan seperti sakit kepala, stress, nyeri otot, ketegangan pada leher, punggung, lengan, bahu dan bagian lain yang berhubungan dengan aktivitas penggunaan komputer [2]. Selain itu, posisi duduk yang statis dan berkelanjutan juga dapat menimbulkan nyeri di beberapa bagian tubuh seperti pada bagian pinggang [3][4].

Keluhan yang dirasakan oleh pekerja tersebut dinamakan dengan musculoskeletal disorder (MSDs), yaitu keluhan pada otot skeletal seperti otot leher, bahu, lengan, tangan, jari, punggung, pinggang dan otot-otot bagian bawah yang dirasakan seseorang [5]. Musculoskeletal disorder yang disebabkan oleh aktivitas - aktivitas yang berhubungan dengan pekerjaan dinamakan dengan Work-Related Musculoskeletal Disorder (WMSDs) [6]. Menurut Peter Vi (2000) dalam Tarwaka dkk (2004) faktor yang menyebabkan terjadinya keluhan musculoskeletal adalah 
aktivitas yang berulang, sikap kerja yang tidak alamiah dan peregangan otot yang berlebihan [6]. Selain itu, durasi kerja yang tinggi yakni 4-8 jam dalam sehari juga dapat meningkatkan resiko MSDs [7].

Salah satu cara untuk menganalisis keluhan otot adalah dengan menggunakan Nordic Body Map (NBM), yaitu kuesioner checklist ergonomi dilengkapi dengan peta tubuh yang digunakan untuk mengidentifikasi letak keluhan musculoskeletal pada pekerja [8]. NBM digunakan karena dapat mengidentifikasi letak keluhan otot secara detail. Beberapa penelitian yang telah dilakukan menggunakan kuesioner Nordic Body Map untuk mengetahui keluhan MSDs yaitu Determination of Musculoskeletal Disorders (MSDs) complaints level with Nordic Body Map (NBM) [9]; Identifikasi risiko ergonomi dengan metode Nordic Body Map terhadap pekerja konveksi sablon baju [10] dan Identifikasi risiko ergonomi operator mesin potong guillotine dengan metode Nordic Body Map [8].

Pegawai divisi Pengelolaan Persampahan DLH Kota Batam menggunakan perangkat komputer pada pekerjaan sehari - hari untuk melakukan perhitungan data, pembuatan laporan, dan aktivitas lainnya. Berdasarkan pengamatan awal, terlihat bahwa banyak pegawai yang bekerja dengan tidak memperhatikan postur kerja yang sesuai dengan aktivitasnya. Oleh karena itu, perlu dilakukan penelitian untuk mengetahui resiko kerja pada pegawai divisi Pengelolaan Persampahan DLH kota Batam agar dapat dilakukan perbaikan pada postur kerja sehingga pegawai dapat bekerja secara aman dan tidak mengganggu performansi kerja.

Office ergonomics adalah ilmu ergonomi yang berkaitan penggunaan perangkat komputer dan kursi pada lingkungan kerja untuk mencapai fasilitas kerja yang aman, nyaman, sehat sehingga diperoleh produktivitas yang optimal [11][12]. Metode yang dapat digunakan untuk menganalisis postur kerja adalah metode Rapid Office Strain Assessment (ROSA). Metode ROSA dilakukan untuk menganalisis postur dan durasi kerja terhadap komponen kursi, monitor, telepon, keyboard dan mouse. Kelebihan metode ini adalah mudah dan cocok dengan lingkungan pekerjaan kantor yang kompleks dimana berkaitan dengan posisi, pencahayaan dan interaksi dengan stasiun kerja [1]. Penilaian resiko kerja pada metode ini memiliki rentang nilai 1 - 10, dimana jika nilai akhir yang dihasilkan adalah lebih dari 5 maka pekerjaan dianggap beresiko dan diperlukan perbaikan pada postur ataupun fasilitas kerja [13]. Beberapa penelitian yang telah menggunakan metode ini untuk menganalisis postur kerja yaitu Musculoskeletal disorders among healthcare network staff using Rapid Office Strain Assessment [4]; Analisis postur kerja untuk mengurangi tingkat resiko kerja menggunakan Rapid Office Strain Assessment (ROSA) [14] dan Evaluation of office ergonomic risk using Rapid Office Strain Assessment (ROSA) [15]. Berdasarkan permasalahan tentang postur kerja pada pegawai divisi Pengelolaan dan Persampahan di Dinas Lingkungan Hidup Kota Batam, maka dilakukan identifikasi keluhan otot dan analisis postur kerja menggunakan kuesioner Nordic Body Map dan metode Rapid Office Strain Assessment (ROSA) untuk mengetahui tingkat resiko postur kerja dan tindakan perbaikan yang harus dilakukan.

\section{II.METODE}

Metode penelitian yang digunakan adalah metode ROSA (Rapid Strain Office Assessment). Sebelum dilakukan pengamatan postur kerja, terlebih dahulu dilakukan identifikasi keluhan otot dengan menggunakan kuesioner Nordic Body Map (NBM). Kuesioner ini dilengkapi dengan peta tubuh yang dibagi menjadi 9 bagian utama yaitu leher, bahu, punggung bagian atas, siku, punggung bagian bawah, pergelangan tangan/tangan, pinggang/pantat, lutut, dan tumit/kaki [8].

Setelah dilakukan identifikasi keluhan, selanjutnya adalah menganalisis postur kerja menggunakan metode ROSA (Rapid Office Strain Assessment). Metode ROSA dilakukan dengan menganalisis postur dan durasi kerja terhadap 3 klasifikasi data. Section A berisikan data postur kerja terhadap komponen kursi. Section B berisikan data postur kerja terhadap komponen monitor dan telepon. Section C berisikan data postur kerja terhadap komponen keyboard dan mouse. Skor dari section B dan section $\mathrm{C}$ kemudian dikalkulasikan sebagai skor monitor and peripherals. Selanjutnya dilakukan perhitungan skor akhir ROSA menggunakan data skor section A dan skor monitor and peripherals. Apabila skor ROSA yang dihasilkan adalah lebih dari 5 maka pekerjaan dianggap beresiko dan diperlukan perbaikan pada postur ataupun fasilitas kerja [15]. 


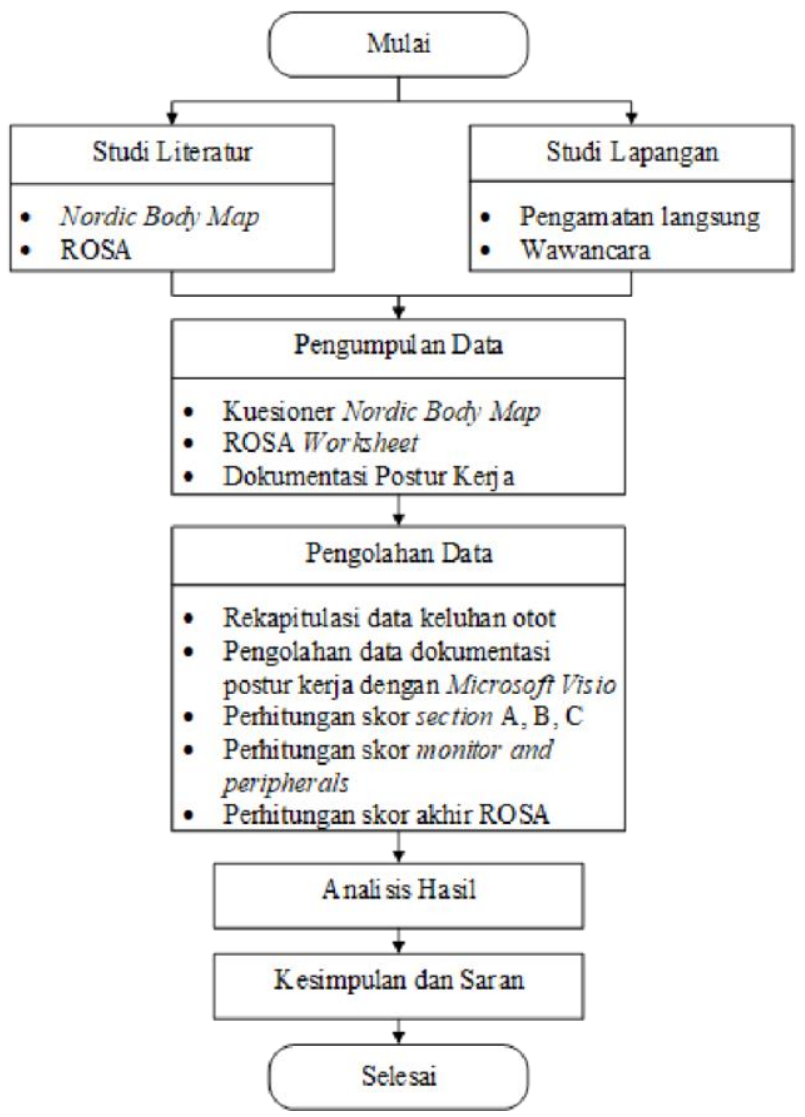

Gambar 1. Flowchart Penelitian

\section{HASIL DAN PEMBAHASAN}

Kuesioner Nordic Body Map yang digunakan menggunakan penilaian skala Guttman yaitu dengan skala jawaban sakit dan tidak sakit, dimana penilaian diberikan terhadap otot pada 28 bagian tubuh. Pengambilan data dilakukan terhadap 6 orang pegawai divisi Pengelolaan dan Persampahan (P2). Pegawai pada divisi ini bekerja selama 7-8 jam per hari dan menggunakan komponen komputer dan kursi dalam bekerja.

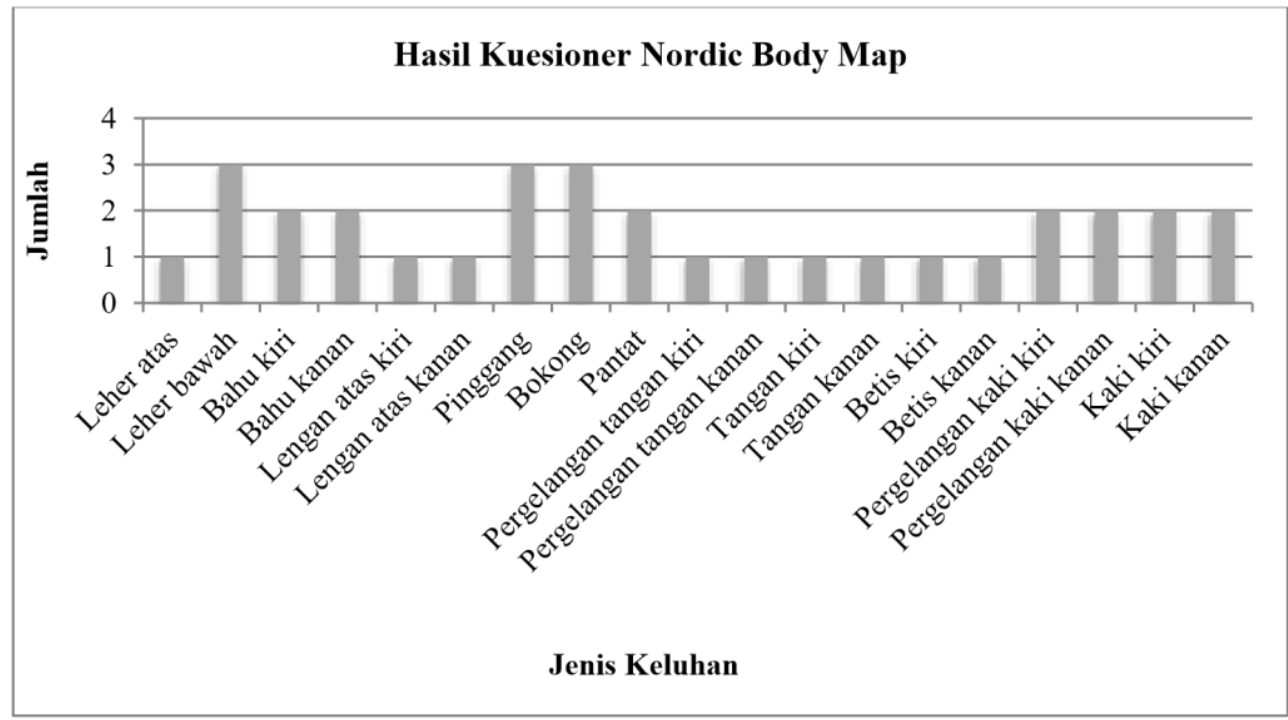

Gambar 2. Hasil Kuesioner Nordic Body Map 
Tabel 1. Data Pegawai P2 DLH Batam

\begin{tabular}{clcc}
\hline No & Nama & Usia & Jenis Pekerjaan \\
\hline 1 & Pegawai A & 40 & Satgas \\
2 & Pegawai B & 23 & Satgas \\
3 & Pegawai C & 26 & Satgas \\
4 & Pegawai D & 25 & Satgas \\
5 & Pegawai E & 32 & Satgas \\
6 & Pegawai F & 40 & Administrasi TPA \\
\hline
\end{tabular}

Berdasarkan data hasil kuesioner Nordic Body Map yang ditunjukkan pada gambar 2.2 dapat diketahui bahwa terdapat 32 keluhan otot yang dialami pekerja. Keluhan otot yang paling banyak dialami oleh pekerja terdapat pada leher bagian bawah, pinggang dan bokong dengan frekuensi masing - masing sebesar 9,375\% dari total keseluruhan keluhan.

\section{A. Penentuan skor section}

Section A menilai postur kerja seseorang terhadap penggunaan komponen kursi. Data yang terdapat pada bagian ini meliputi data ketinggian kursi, data kedalaman kursi, data sandaran tangan dan data sandaran punggung. Berikut merupakan data hasil pengamatan yang telah dilakukan.

Tabel 2. Data Ketinggian Kursi

\begin{tabular}{|c|c|c|c|c|}
\hline Nama & Sudut kaki yang terbentuk & Posisi kaki dengan meja & engaturan ketinggian kursi & Skor \\
\hline Pegawai $A$ & $\mathrm{~A} \quad>90^{\circ}$ & Kaki tidak menyentuh meja & 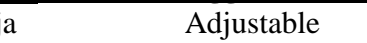 & 2 \\
\hline Pegawai B & $<90^{\circ}$ & Kaki tidak menyentuh meja & Non-Adjustable & 3 \\
\hline Pegawai C & $90^{\circ}$ & Kaki tidak menyentuh meja & Non-Adjustable & 2 \\
\hline Pegawai D & $90^{\circ}$ & Kaki tidak menyentuh meja & Non-Adjustable & 2 \\
\hline Pegawai E & $>90^{\circ}$ & Kaki menyentuh meja & Adjustable & 3 \\
\hline Pegawai $\mathrm{F}$ & $>90^{\circ}$ & Kaki tidak menyentuh meja & Adjustable & 2 \\
\hline
\end{tabular}

Tabel 3. Data Kedalaman Kursi

\begin{tabular}{cccc}
\hline Nama & Jarak ujung kaki dengan lutut & Pengaturan kedalaman kursi & Skor \\
\hline Pegawai A & Kurang dari 3 inci & Non-Adjustable & 3 \\
Pegawai B & Lebih dari 3 inci & Non-Adjustable & 3 \\
Pegawai C & Lebih dari 3 inci & Non-Adjustable & 3 \\
Pegawai D & Lebih dari 3 inci & Non-Adjustable & 3 \\
Pegawai E & Kurang dari 3 inci & Non-Adjustable & 3 \\
Pegawai F & Kurang dari 3 inci & Non-Adjustable & 3 \\
\hline
\end{tabular}

Tabel 4. Data Sandaran Tangan

\begin{tabular}{lcccc}
\hline Nama & Posisi sandaran tangan & Pengaturan sandaran tangan & Tekstur sandaran tangan & Skor \\
\hline Pegawai A & Mendukung & Non-Adjustable & Permukaan keras & 3 \\
Pegawai B & Tidak ada & Non-Adjustable & - & 3 \\
Pegawai C & Tidak ada & Non-Adjustable & - & 3 \\
Pegawai D & Tidak ada & Non-Adjustable & - & 3 \\
Pegawai E & Mendukung & Non-Adjustable & Permukaan keras & 3 \\
Pegawai F & Mendukung & Non-Adjustable & Permukaan keras & 3
\end{tabular}


Tabel 5. Data Sandaran Punggung

\begin{tabular}{rcccc}
\hline Nama & Posisi sandaran punggung & Posisi permukaan meja kerja & Pengaturan sandaran punggung Skor \\
\hline Pegawai A & Memadai & Tidak tinggi & Non-Adjustable & 2 \\
Pegawai B & $>110^{\circ}$ & Terlalu tinggi & Non-Adjustable & 4 \\
Pegawai C & $<95^{\circ}$ & Terlalu tinggi & Non-Adjustable & 4 \\
Pegawai D & Memadai & Tidak tinggi & Non-Adjustable & 2 \\
Pegawai E & Memadai & Tidak tinggi & Non-Adjustable & 2 \\
Pegawai F & $>110^{\circ}$ & Tidak tinggi & Non-Adjustable & 3 \\
\hline
\end{tabular}

Tabel 6. Skor Kursi

\begin{tabular}{ccc}
\hline Nama & Durasi & Skor Kursi \\
\hline Pegawai A & $>4$ jam/ hari & 5 \\
Pegawai B & $>4$ jam/ hari & 4 \\
Pegawai C & $>4$ jam/ hari & 7 \\
Pegawai D & $>4$ jam/ hari & 5 \\
Pegawai E & $>4$ jam/ hari & 6 \\
Pegawai $F$ & $>4$ jam/ hari & 5 \\
\hline
\end{tabular}

\section{B. Penentuan skor section b}

Section B menilai postur kerja seseorang terhadap penggunaan komponen monitor dan telepon. Berikut merupakan data hasil pengamatan yang telah dilakukan.

Tabel 7. Data Penggunaan Monitor

\begin{tabular}{|c|c|c|c|c|c|}
\hline Nama & Posisi monitor & hayaan monitor silau & Penyangga dokumen & Durasi & \\
\hline Pegawai A & Terlalu rendah, terlalu jauh & Tidak & Tidak ada & $>4 \mathrm{jam} /$ hari & 5 \\
\hline Pegawai B & Sejajar & Tidak & Tidak ada & $>4 \mathrm{jam} /$ hari & 3 \\
\hline Pegawai C & Terlalu rendah & Tidak & Tidak ada & $>4 \mathrm{jam} /$ hari & 4 \\
\hline Pegawai D & Terlalu rendah & Tidak & Tidak ada & $>4 \mathrm{jam} /$ hari & 4 \\
\hline Pegawai E & Terlalu rendah & Tidak & Tidak ada & $>4$ jam/ hari & 4 \\
\hline Pegawai F & Sejajar & Tidak & Tidak ada & $>4 \mathrm{jam} /$ hari & 3 \\
\hline
\end{tabular}

Tabel 8. Data Penggunaan Telepon

\begin{tabular}{|c|c|c|c|c|}
\hline Nama & Posisi telepon dengan pekerja & Alternatif hands-free & $\underline{\text { Durasi }}$ & $\underline{\text { Skor }}$ \\
\hline Pegawai A & $<30 \mathrm{~cm}$ & Ada & 1 jam \& kontinyu & 2 \\
\hline Pegawai B & $>30 \mathrm{~cm}$ & Tidak ada & $<1$ jam & 2 \\
\hline Pegawai C & $>30 \mathrm{~cm}$ & Tidak ada & $<1$ jam & 2 \\
\hline Pegawai D & $>30 \mathrm{~cm}$ & Tidak ada & $<1$ jam & 2 \\
\hline Pegawai E & $>30 \mathrm{~cm}$ & Tidak ada & $<1$ jam & 2 \\
\hline Pegawai F & $>30 \mathrm{~cm}$ & Tidak ada & $<1$ jam & 2 \\
\hline
\end{tabular}

Tabel 9. Skor Monitor dan Telepon

\begin{tabular}{cc}
\hline Nama & Skor monitor dan telepon \\
\hline Pegawai A & 4 \\
Pegawai B & 3 \\
Pegawai C & 3 \\
Pegawai D & 3 \\
Pegawai E & 4 \\
Pegawai F & 3 \\
\hline
\end{tabular}




\section{Penentuan skor section c}

Section C menilai postur kerja seseorang terhadap penggunaan komponen mouse dan keyboard.

Berikut merupakan data hasil pengamatan yang telah dilakukan.

Tabel 10. Data Penggunaan Mouse

\begin{tabular}{ccccc}
\hline Nama & Posisi mouse & Posisi pinch grip & Durasi & Skor \\
\hline Pegawai A & Menjangkau mouse & Tidak & $>4 \mathrm{jam} /$ hari & 3 \\
Pegawai B & Sejajar dengan bahu & Tidak & $>4 \mathrm{jam} /$ hari & 2 \\
Pegawai C & Sejajar dengan bahu & Tidak & $>4 \mathrm{jam} / \mathrm{hari}$ & 2 \\
Pegawai D & Sejajar dengan bahu & Tidak & $>4 \mathrm{jam} / \mathrm{hari}$ & 2 \\
Pegawai E & Menjangkau mouse & Tidak & $>4 \mathrm{jam} /$ hari & 3 \\
Pegawai F & Sejajar dengan bahu & Tidak & $>4 \mathrm{jam} /$ hari & 2 \\
\hline
\end{tabular}

Tabel 11. Data Penggunaan Keyboard

\begin{tabular}{cccccc}
\hline Nama & Sudut tangan & Posisi keyboard & Posisi meja keyboard & Durasi & Skor \\
\hline Pegawai A & $>15^{\circ}$ & Terlalu tinggi & Non-Adjustable & $>4$ jam/hari & 5 \\
Pegawai B & $>15^{\circ}$ & Terlalu tinggi & Non-Adjustable & $>4$ jam/hari & 5 \\
Pegawai C & Tangan lurus & Terlalu tinggi & Non-Adjustable & $>4$ jam/hari & 4 \\
Pegawai D & $>15^{\circ}$ & Terlalu tinggi & Non-Adjustable & $>4$ jam $/$ hari & 5 \\
Pegawai E & $>15^{\circ}$ & Tidak tinggi & Non-Adjustable & $>4$ jam $/$ hari & 5 \\
Pegawai F & Tangan lurus & Tidak tinggi & Non-Adjustable & $>4$ jam $/$ hari & 3 \\
\hline
\end{tabular}

Tabel 12. Skor Mouse dan Keyboard

\begin{tabular}{cc}
\hline Nama & Skor mouse dan keyboard \\
\hline Pegawai A & 6 \\
Pegawai B & 5 \\
Pegawai C & 4 \\
Pegawai D & 6 \\
Pegawai E & 5 \\
Pegawai F & 3 \\
\hline
\end{tabular}

\section{Penentuan skor peripherals and monitor}

Skor pada bagian ini ditentukan berdasarkan data dari section B (skor monitor dan telepon) dan section C (skor mouse dan keyboard). Skor peripherals and monitor masing-masing pekerja ditunjukkan pada tabel 13.

Tabel 13. Skor Peripherals and Monitor

\begin{tabular}{|c|c|c|c|}
\hline Nama & Skor Kursi & $\frac{\text { Skor peripherals and }}{\text { monitor }}$ & $\underline{\text { Skor ROSA }}$ \\
\hline Pegawai A & 4 & 6 & 6 \\
\hline Pegawai B & 3 & 5 & 5 \\
\hline Pegawai C & 3 & 4 & 4 \\
\hline Pegawai D & 3 & 6 & 6 \\
\hline Pegawai E & 4 & 5 & 5 \\
\hline Pegawai F & 3 & 3 & 3 \\
\hline
\end{tabular}

\section{E. Penentuan skor rosa}

Skor pada bagian ini ditentukan berdasarkan data dari skor kursi dan skor peripherals and monitor. Skor ROSA masing - masing pekerja ditunjukkan pada tabel 14. 
Tabel 14. Skor ROSA

\begin{tabular}{|c|c|c|c|c|}
\hline Nama & Skor Kursi & $\frac{\text { Skor peripherals and }}{\text { monitor }}$ & $\underline{\text { Skor ROSA }}$ & $\underline{\text { Keterangan }}$ \\
\hline Pegawai A & 5 & 6 & 6 & Beresiko \\
\hline Pegawai B & 4 & 5 & 5 & Tidak Beresiko \\
\hline Pegawai C & 7 & 4 & 7 & Beresiko \\
\hline Pegawai D & 5 & 6 & 6 & Beresiko \\
\hline Pegawai E & 6 & 5 & 6 & Beresiko \\
\hline Pegawai F & 5 & 3 & 5 & Tidak Beresiko \\
\hline
\end{tabular}

Berdasarkan perhitungan skor ROSA dapat diketahui bahwa 4 dari 6 pegawai memiliki skor ROSA diatas 5 , dimana hal ini dianggap postur kerja pegawai tersebut beresiko. Faktor resiko ini terjadi karena masih adanya pegawai yang belum memperhatikan sisi ergonomi dalam bekerja, seperti posisi dalam menjangkau mouse yang terlalu jauh dan posisi mengetik yang masih tidak lurus (membuat pergelangan tangan menekuk ke atas). Selain itu, fasilitas kantor juga mempengaruhi faktor resiko dari postur kerja pegawai. Hal ini terlihat dari masih adanya fasilitas kantor yang belum memperhatikan sisi ergonomi, seperti penggunaan kursi yang belum adjustable pada beberapa pegawai, tidak adanya documents holder, meja yang terlalu tinggi terhadap beberapa orang dan layar monitor yang kecil. Berdasarkan hasil wawancara, diketahui bahwa adanya komponen kursi yang rusak, sehingga fungsi - fungsi penting pada kursi seperti pengaturan ketinggian kursi tidak dapat digunakan sebagaimana mestinya. Kurangnya kesadaran pegawai dan fasilitas kantor yang mendukung berpengaruh terhadap timbulnya keluhan MSDs yang dirasakan oleh pegawai. Oleh karena itu diperlukan adanya perbaikan untuk mendukung kenyamanan, kesehatan dan keselamatan dalam bekerja.

Setelah mengetahui keluhan musculoskeletal dan skor ROSA pada pekerja, maka usulan tindakan perbaikan yang dapat diberikan guna mengurangi timbulnya keluhan otot adalah sebagai berikut.

1) Penerapan prinsip ergonomi dalam bekerja

Sikap kerja yang harus diperbaiki adalah sebagai berikut.

a) Ketinggian kursi saat bekerja diatur agar posisi lutut rileks dan membentuk sudut $90^{\circ}$

b) Adanya sandaran tangan pada kursi pekerja. Hal ini digunakan untuk mengurangi keluhan otot pada lengan dan siku. Sandaran yang baik memiliki tekstur permukaan yang tidak keras.

c) Adanya sandaran punggung pada kursi untuk mengurangi timbulnya keluhan otot bagian pada bagian punggung. Posisi duduk yang baik adalah $95^{\circ}-110^{\circ}$

d) Posisi pergelangan tangan saat mengetik lurus dan tidak menekuk ke atas.

e) Pengaturan monitor yang berjarak $40-75 \mathrm{~cm}$ dari pekerja dan sejajar dengan pandangan mata sehingga meminimalisir kelelahan pada otot leher dan mata.

Salah satu media sosialisasi yang dapat digunakan untuk memvisualisasikan postur kerja standar adalah dengan penggunaan poster office ergonomics pada lingkungan kerja. Hal ini dikarenakan, poster merupakan media yang efektif dalam mempercepat pemahaman pembaca terhadap pesan yang disajikan [16].

2) Perbaikan fasilitas kerja

Hal ini perlu dilakukan karena masih adanya fasilitas kerja yang belum mendukung sisi ergonomi, seperti penggunaan kursi yang tidak adjustable yang tidak sesuai dengan postur pekerja sehingga menimbulkan keluhan otot di tubuh bagian belakang. Penerapan kursi adjustable ini merupakan hal yang penting, karena selain berpengaruh pada postur terhadap komponen kursi itu sendiri, kursi adjustable juga dapat memberi pengaruh terhadap ketinggian penggunaan meja pada pekerja. Selanjutnya, mengingat banyaknya keluhan pada leher yang terjadi pada pekerja, maka disarankan agar pekerja menggunakan document holders. Penggunaan documents holder ini dapat mengurangi resiko timbulnya keluhan otot di bagian leher.

3) Melakukan peregangan otot dan olahraga rutin

Peregangan otot dapat dilakukan selama 10-15 menit setiap 1 jam bekerja [17]. Sementara, olahraga seperi gymnastic dan jogging dapat dilakukan seminggu sekali untuk meningkatkan sirkulasi darah dan menurunkan resiko keluhan otot [18][19].

Ketiga usulan perbaikan yang diberikan dapat mengurangi resiko terjadinya keluhan otot pada pegawai sehingga pegawai dapat bekerja secara lebih aman, nyaman dan tidak mengganggu performansi kerja akibat adanya keluhan otot. 


\section{KESIMPULAN}

Berdasarkan hasil analisis dan perhitungan yang telah dilakukan, diketahui bahwa terdapat 32 keluhan otot yang dialami pekerja dengan keluhan otot terbanyak terdapat pada bagian leher bagian bawah, pinggang dan bokong dengan masing - masing frekuensi sebesar 9,375\%. Berdasarkan penilaian postur kerja dengan metode ROSA diketahui bahwa 4 dari 6 pegawai memiliki skor ROSA lebih dari 5 yang memiliki arti bahwa postur kerja pegawai tersebut beresiko. Adanya keluhan otot yang dialami pekerja dan postur kerja yang beresiko ini mengindikasikan bahwa diperlukannya tindakan perbaikan. Tindakan perbaikan yang dapat dilakukan oleh Dinas Lingkungan Hidup Kota Batam adalah melakukan sosialisasi penerapan ergonomi di kantor, perbaikan fasilitas kerja dan melakukan peregangan otot serta olahraga rutin bagi para pekerja.

\section{REFERENSI}

[1] Matos, M., dan Pedro M.A. 2015. Ergonomic Evaluation Of Office Workplaces With Rapid Office Strain Assessment (ROSA). 6th International Conference on Applied Human Factors and Ergonomics (AFHE 2015) and the Affiliated Conferences. 26-30 Juli 2015, Las Vegas, USA. pp.4689-4694.

[2] Watchman, G. R. 1997. Working Safely with Video Display Terminals. U.S Department of Labor. USA.

[3] Callaghan, J. P., dan Nadine, M. D. 2002. Examination of The Flexion Relaxation Phenomenon in Erector Spinae Muscles During Short Duration Slumped Sitting. Clinical Biomechanics, 17(5):353-360.

[4] Lotfollahzadeh, A., Arefi, M.F., Gurjan, H.E., Razagari, N., Ebadi, B., dan Babaei-Pouya, A. 2019. Musculoskeletal Disorders among Healthcare Network Staff using Rapid Office Strain Assessment. International Journal of Musculoskeletal Pain Prevention, 4(4):270-276.

[5] Tarwaka, Bakri, S.H.A., Sudiajeng L. 2004. Ergonomi untuk Keselamatan, Kesehatan Kerja dan Produktivitas. Edisi ke-1, UNIBA PRESS. Surakarta.

[6] Bernard, B. P., dan Putz-Anderson, V. 1997. Musculoskeletal Disorders And Workplace Actors; A Critical Review Of Epidemiologic Evidence For Workrelated Musculoskeletal Disorders Of The Neck, Upper Extremity, And Low Back. Jurnal Teknik Industri, 19(1):97-106.

[7] Dinar, A., Susilowati, I.H., Azwar, A., Indriyani, K., dan Wirawan, M. 2018. Analysis of Ergonomic Risk Factors in Relation to Musculoskeletal Disorder Symptoms in Office Workers. International Conference of Occupational Health and Safety. 2017. 1-2 November 2017. Bali, Indonesia. pp.16-29.

[8] Rahdiana, N. 2017. Identifikasi Risiko Ergonomi Operator Mesin Potong Guillotine Dengan Metode Nordic Body Map. Jurnal Industry Xplore, 2(1):1-12.

[9] Sofyan, D.K., dan Amir. 2019. Determination of Musculoskeletal Disorders (MSDs) complaints level with Nordic Body Map (NBM). International Conference on Industrial and Manufacturing Engineering. 16-17 Oktober 2018. Medan, Indonesia. pp.1-6.

[10] Wijaya, K. 2019. Identifikasi Risiko Ergonomi dengan Metode Nordic Body Map Terhadap Pekerja Konveksi Sablon Baju. Konferensi Nasional IDEC. 2-3 Mei 2019. Surakarta. pp.B08.1-B08.9.

[11] Kroemer, K.H.E. 2001. Office Ergonomic. USA: CRC Press.

[12] Worksafe Travail Securitaire. 2010. Office Ergonomics Guidelines For Preventing Muculoskeletal Injuries. https://www.travailsecuritairenb.ca/media/1599/officeedist-1.pdf. Diakses tanggal 11 Desember 2020.

[13] Sonne, M., Villata, D.L., Andrews D.M. 2012. Development and Evaluation Of An Office Ergonomic Risk Checklist: ROSA-Rapid Office Strain Assessment. Applied Ergonomics,43(1):98-108.

[14] Erliana, C.T., dan Munadya Z. 2019. Analisis Postur Kerja Untuk Mengurangi Tingkat Risiko Kerja Menggunakan Metode Rapid Office Strain Assessment (ROSA). Talenta Conferenece Series: Energy \& Engineering. 2(3):513-522.

[15] Jayadi, E.L., Jodiawan, P., Yamani, A.Z., dan Qurthuby M. 2020. Evaluation of Office Ergonomic Risk using Rapid Office Strain Assessment (ROSA). Journal of Industrial Engineering and Management Systems. 13(1):47-51.

[16] Ewles, L., dan Simnett, I. 1994. Promosi Kesehatan Petunjuk Praktis. Edisi ke-2, UGM Press. Yogyakarta.

[17] Rahayu, P.T., Setyawati, M.E., Arbitera, C., dan Amrullah, A.A. 2020. Relationship of Individual and Occupational Factors to Complaints of Musculoskeletal Disorders among Employees. Jurnal Kesehatan. 11(3):449-456.

[18] Nurhikmah. 2011. Factors Associated with Musculoskeletal Disorders (MSDs) in Furniture Workers in the Benda Kota District of Tangerang in 2011. Undergraduate Thesis. Jakarta: Faculty of Medicine and Health Sciences Universitas Islam Negeri Syarif Hidayatullah.

[19] Putri, B.A. 2019. The Correlation between Age, Years of Service, and Working Postures and the Complaints of Musculoskeletal Disorders. The Indonesian Journal of Occupational Safety and Health, 8(2):187-196. 